\title{
장애평가 지침의 필요성
}

이 호 승

울산대학교 의과대학 서울아산병원 정형외과

\section{Necessity of developing a disability evaluation guideline}

\section{Ho Seong Lee, MD}

Department of Orthopaedic Surgery, Asan Medical Center, University of Ulsan College of Medicine, Seoul, Korea

Background: Although doctors expend their best effort in treating their patients' illnesses or injuries, the patients may retain some disabilities even after treatment. Accordingly, some conflicts occur between the patients' expectations of financial compensation for their disabilities and the financial manager's policy to efficiently distribute limited resources. The mediation of these social conflicts requires the determination of the degree of physical disability, which can be done by doctors alone. Hence, a reliable disability evaluation guideline should be established. However, currently, only a few educational programs on disability evaluation are available for doctors and there is no reliable guideline for disability evaluation.

Current Concepts: There were attempts to implement the American Medical Association guideline in Korea; however, it is currently not being used efficiently because it is quite complicated and unsuited to Korean settings. Mcbride's disability evaluation, published 60 years ago, is being used, but it is not realistic and unreasonable in Korea. To prepare a standard guideline for disability evaluation, the Korean Academy of Medical Sciences published a booklet, "Disability Evaluation Guideline: Explanation and Case Studies", based on the American Medical Association guideline. The academy published the booklet's revised version (2nd edition), 'Disability evaluation guideline and utilization', in 2016. However, Korean Academy of Medical Sciences guideline still not being used because it is too complicated to use.

Discussion and Conclusion: Fair disability evaluation is a social responsibility given to doctors, and there should be a useful guideline for disability evaluation that reflects the characteristics of each medical society or association.

Key Words: Disability evaluation; Guideline; Social responsibility; Medical society

장애진단서를 발부해 달라고 하는 환자들이 점차 늘어나 고 있다. 얼마 전 외과에서 맥브라이드(McBride) 장애평가 법을 기준으로 장애판정을 한다는 애기를 듣고 의아한 적이 있다. 70 여 년 전 미국의 정형외과 의사가 제안한 장애기준

Received: July 15, 2021 Accepted: July 21, 2021

Corresponding author: Ho Seong Lee

E-mail: hosng@amc.seoul.kr

\section{(c) Korean Medical Association}

This is an Open Access article distributed under the terms of the Creative Commons Attribution Non-Commercial License (http://creativecommons. org/licenses/by-nc/3.0) which permits unrestricted non-commercial use, distribution, and reproduction in any medium, provided the original work is properly cited.
안을 아직도 우리나라에서 정형외과가 아닌 분야에서 장애 판정 기준안으로 사용하고 있다는 사실은 잘 납득이 되지 않 는다. 이 논문에서는 국내에서 적용 가능하고, 보다 현실적 인 장애판정 기준안 마련의 필요성에 대하여 논하고자 한다.

여러 가지 질병이나 손상에 대하여 최선의 치료 후에도 후 유장애가 남을 수 있다. 완벽한 치료란 불가능하며, 따라서 어느 정도 남게 되는 불완전함에 대하여 어디까지 장애로 인 정하고 보상할 것인지를 판정하는 것은 쉽지 않은 일이다. 세계보건기구가 59 개 국가의 평균 장애 출현율을 도출한 결 과가 $15.6 \%$ 로 추정되는데, 고소득 국가에서는 $11.8 \%$, 저소 득 국가에서는 $18.0 \%$ 로 추정되었다[1]. 장애의 정의와 범주 
는 그 나라의 사회 문화적, 경제적, 정치적 여건과 수준에 따 라서도 다를 수 있다. 미국과 영국에서 장애인의 사회보장 요구가 거절되어 소송에 이른 경우 중 $50 \%$ 에서 장애판정이 바뀌었다고 보고되고 있다[2].

원상으로 회복되지 않은 아쉬움에 대하여 재정적 보상을 받고자 하는 환자와 한정된 재원을 효율적으로 분배하고자 하는 재원 관리자의 입장 사이에 갈등이 존재하는것은 당연 하다. 재원이 무한하여 환자가 원하는 대로 보상해 주면 문 제될 것이 없지만 그런 세상은 존재하지 않는다. 이러한 갈 등 중재의 기준이 신체적 장애 정도를 판정하는 것이다. 환 자에게 남은 장애가 어느 정도인지 공정하고 정확하게 판단 하여 제시하는 것이 무엇보다도 중요하고, 이는 의사만이 할 수 있는 일이다. 한정된 재원을 분배함에 있어 더 불편한 사 람이 더 많은 지원을 받아야 하는 것이 당연하다. 장애 정도 를 수치화하였을 때 $5 \%$ 의 장애가 남은 환자가 $10 \%$ 의 장애 가 남은 환자보다 더 높은 보상을 받는다면 공정하지 않은 것이다. 피해자는 더 많은 보상을 받기 위해서 자신의 장애 를 과장하고 싶은 것이 인지상정이다. 장애와 보상 판정의 기준인 장애 정도의 추정은 의사가 하여야 하는데 무조건 환 자에게 유리한 장애판정을 하여야 한다는 생각은 공정보다 는 안일함이다. 대부분의 재원은 한정되어 있는데 '내 돈도 아닌데 공연히 의사가 욕먹을 일 생기지 않도록 무조건 환자 가 원하는 방향으로 판정해주자'는 생각은 전문가에게 주어 진 사회적 책무를 져버리는 것이다. 공정하게 배분되지 않아 고갈된 재원의 부족분은 결국 또 다른 보험 가입자가, 국민 이, 사회가 부담하는 것이다. 보상을 책임질 기관의 입장에 치우쳐도 안 되지만 보상을 더 받고 싶은 피해자의 입장만을 대변하는 것도 올바른 전문가의 자세라고 할 수 없다.

의사들은 치료 과정에서는 최선을 다하지만 치료 후에 남 게 되는 장애 정도의 추정에는 관심이 없거나 소홀한 경우가 많다. 우리 의학교육 과정에서는 장애판정 방법에 대한 교육 이 이루어지지 않고, 개인적으로 공부할 기회도 많지 않으 며, 참고할 만한 기준안도 마땅치 않다보니 똑같은 환자에 대한 장애 정도의 추정 결과가 의사마다 편차가 너무 커서 의사의 신뢰를 떨어뜨리는 대표적인 계기가 되고 있다. 최근 장애판정의 불만을 가진 환자가 의사에게 칼부림을 하는 황
당한 일도 발생하였다. 인터넷에는 의사가 보험사로부터 로 비를 받아 장애평가가 편향되었다는 불만이 많지만 이는 대 부분 사실이 아니다. 이러한 오해는 장애 정도의 추정값이 의사에 따라 편차가 크기 때문에 발생한 것이고, 이는 교육 의 문제 외에도 장애판정 기준안의 부재가 큰 원인이다. 장 애평가 기준이 애매하면 이를 근거로 한 판정 결과 또한 공 정하지 않을 것이다. '장애판정 기준의 부재'는 '법전 없이 내 린 판결'과 같은 것이다.

현재 장애판정 기준으로 가장 널리 사용되고 있는 맥브 라이드 법[3]은 미국의 맥브라이드라는 정형외과 의사가 1936년에 초판을 발행한 후, 1963 년 이후 개정되지 않아 현실에 맞지 않는 부분이 너무 많은데, 이 기준안이 현재 까지도 국내 비정형외과 분야에서도 사용되고 있다는 사실 이 실로 놀라운 일이다. 미국의학협회(American Medical Association, AMA)에서는 1956년 신체장애등급 위원회를 구성하고 1958 년부터 1970 년까지 무려 12 년에 걸쳐 각 분 과학회별로 Journal of the American Medical Association 에 해당 분야의 신체장애판정 평가방법에 관하여 13 개의 독 립적인 논문으로 발표하였다. 1971년 60명 학자들의 공동저 술로 '신체장애 평가지침'을 발행하였으며, 이후 수차례에 걸 쳐 수정하여 2008년에 6판을 발행하였다[4]. 그러나 발간 8 개월 만에 50 쪽에 달하는 많은 수정이 가해질 정도로 미진한 부분이 많았으며, 현재 미국 내에서도 16 개 주에서는 AMA 의 지침을 사용치 않고 있고, $\mathrm{AMA}$ 지침을 사용하는 주에서 도 각 주마다 3 판, 4 판, 5 판, 6 판 등 다르게 선택하여 사용하 고 있는 실정이다[2]. 국내에서도 $\mathrm{AMA}$ 의 지침을 사용하고 자 하는 시도가 있었지만, 너무 복잡하고 우리 현실과 맞지 않아 잘 사용되지 않고 있다. 그 외에도 현재 국내에서 여러 단체별로 많은 장애판정 기준이 사용되고 있으며, 대부분 신 체장애를 14 개의 등급으로 구분하고 있다. 이러한 장애등급 제는 1953년 근로기준법 제정 시 처음 채택되었으나, 그 근 간이 된 장애등급의 장애항목과 장애보상액수의 산정방법은 1947 년의 일본노동기준법과 매우 유사하다[2].

국내 현실에 맞는 장애평가 기준안을 마련하고자 대한의학 회에서도 2011년 AMA식 평가법을 근간으로 '장애평가기준: 해설과 사례연구'란 책자를 발간한 바 있고[5], 2016년 9월 
개정판(2판) '장애평가기준과 활용'을 발간하였다다[6]. 그러 나 일부 내용에 대한 논란이 지속되고 있고, 실제 적용 시에 여러 문제점이 있어 현재 사용되고 있지 않다. 가장 큰 문제 는 개정된 장애평가안이 기존에 주로 사용되고 있던 평가 기 준과 장애판정값의 괴리가 커서 적용 시 저항이 컸기 때문이 다. 예를 들어 기존 방식대로 적용하면 $10 \%$ 의 장애가 새로운 평가방법에 의하면 $20 \%$ 로 커지던지, 아니면 $5 \%$ 로 반감하면 이해 당사자 모두를 납득시키기 어렵기 때문에 받아들여질 수 없는 것이다. 최종 장애율의 차이는 직업계수의 적용 여부 에 따라 많이 다르게 산출되었는데, 직업을 반영하는 방식에 있어 과별로 일관되게 적용되지 않았기 때문에 최종 장애 산 출값의 차이가 크게 나타났다. 언뜻 생각하면 직업을 고려한 장애 정도의 보정이 필요할 수 있지만 다양한 직업의 반영은 의사의 판단 영역을 넘어서는 것이라고 생각한다.

장애 정도의 추정은 상대적일 수밖에 없다. 예를 들어 발 가락 절단으로 인한 보행장애는 $5 \%$ 장애 또는 $10 \%$ 장애 등 절대값으로 정할 수 없는 것이다. Colostomy bag을 차고 생 활하여야 하는 장루 환자와 엄지발가락 절단 환자는 누가 더 장애가 크다고 해야 할까? 한쪽 눈의 실명과 한쪽 다리의 비 골신경 마비로 인한 보행장애 환자는 누가 더 생활의 제한이 많을까? 그리고 이러한 장애는 국가별로 생활패턴에 따라서 도 다르게 평가되어야 할 것이다. 좌식생활을 하는 한국인과 실내에서도 신발을 신고 다니는 서양인에서의 의족의 불편 함은 다를 것이다. 장애 정도의 상대적 추정은 결국 여러 가 지 현실을 반영하여 전문가들의 논의와 합의로써 도출되는 것이다[7]. 정형외과학회에서는 2005년 나름의 평가기준안 을 제시하였고[8], 이를 수정 보완하여 2020년 맥브라이드 장애평가법을 현실에 맞게 보완한 이른바 '한국형 장애평가 안을 제시하였다[9].

현재 국내 장애판정 건수의 약 50-60\%는 사지와 척추 분 야이고, 나머지 사례가 여러 분야로 나누어져 있어, 전문과 목에 따라서는 장애판정의 필요성이 간과될 수 있다. 그러 나 앞에서 언급하였듯이 공정한 장애평가는 의사에게 주어 진 사회적 책무로 각 전문과목의 특성을 반영한 '쓸만한' 장 애평가 기준안이 있어야 할 것이다. 대한의학회에서 만들었 던 장애평가 기준을 참고로 하거나 AMA 6판을 기준으로 하
거나 아니면 맥브라이드법을 참고로 하던지 각 학회에서 전 문가들의 논의를 거쳐 가급적 논란이 적은 현실적 기준안이 마련되어야 할 것이다. 부위별로 상대적인 장애 정도는, 예 를 들면 위 절제술과 대장 절제술과의 장애 정도를 비교하는 것은 분과별로 마련하여야 하겠지만 전문과목 간의 장애 정 도를 비교하는 것은 대한의학회가 나서야 할 것이다. 전문과 목 간의 장애 정도를 조율하는 것은 사실 이해관계가 충돌하 는 것이 아니다. 전문과목별로 장애 정도를 높여 평가하는 것이 해당 전문과목에 유리할 것이 없으며, 이는 보험수가를 더 많이 받고자 하는 전문과목별 노력과 전혀 다른 것임으로 조금만 관심을 기울여 조율하면 더 합리적인 한국형 장애평 가 기준안을 만들 수 있을 것이다. 과거의 시행착오를 교훈 삼아, 보다 현실적이고 공정한 한국형 장애판정 기준안이 각 전문학회별로 마련되어야 할 것이다.

찾아보기말: 장애평가; 지침; 사회적 책무; 학회

\section{ORCID}

Ho Seong Lee, https://orcid.org/0000-0002-2336-9498

\section{Conflict of Interest}

No potential conflict of interest relevant to this article was reported.

\section{References}

1. World Health Organization; World Bank. World report on disability. Geneva: World Health Organization; 2011.

2.Lee SH, Park SJ, Park JH. McBride's disability assessment: why is it still most used? J Korean Orthop Assoc 2020;55:366-373.

3.McBride ED. Disability evaluation and principles of treatment of compensable injuries. 6th ed. Philadelphia: JB Lippincott; 1963.

4. American Medical Association. Guides to the evaluation of permanent impairment. 6th ed. Chicago: American Medical Association; 2008.

5. Korean Academy of Medical Sciences. Guides for the evaluation of permanent impairment: commentary and case studies. Seoul: Bakyang Publishing; 2011.

6. Korean Academy of Medical Sciences. Guideline of disability evaluation and it's utilization. 2nd ed. Seoul: Academya; 2016.

7. Korean Orthopaedic Association. Orthopaedics. 8th ed. Seoul: Choesinuihaksa; 2020.

8. Korean Orthopaedic Association. Disability evaluation. 1st ed. Seoul: Choesinuihaksa; 2005.

9. Korean Orthopaedic Association. Update of McBride's disability assessment: extremities and spine. Disability evaluation. Seoul: Mincom; 2020. 